\title{
Power quality in high voltage mains supplying mainline railroads' traction substations
}

\author{
Bulatov Yu.N. ${ }^{1,}$, Kryukov A.V. ${ }^{2,3}$, Cherepanov A.V. ${ }^{2}$ \\ ${ }^{1}$ Bratsk State University, Bratsk, Russia \\ ${ }^{2}$ Irkutsk State Transport University, Irkutsk, Russia \\ ${ }^{3}$ Irkutsk National Research Technical University, Irkutsk, Russia
}

\begin{abstract}
The increase in the trains weight and their operation speeds leads to considerable growth of abrupt-variable, non-linear and one-phase traction loads. This, in its own turn, leads to significant deviations, unsymmetry and voltage harmonic distortions in $110-220 \mathrm{kV}$ mains adjacent to traction substations of AC railroads. Significant deterioration in power quality factors is observed in Siberian and Far East regions where 110-220 kV main power transmission lines are immediately adjacent to Transsib traction substations; in this case, in points with lower levels of short circuit power, power quality factors exceed by far the permissible levels. The articles provides the results of studies aimed at solution of power quality enhancement is-sues for mains adjacent to traction substations of Trans-Siberian Railway. To enhance power quality in mains supplying traction substations, smart grid technologies can be used together with multiagent control systems. Technical solutions, based on the results obtained, are proposed that allow to bring the power quality factors to the regulatory values. Due to a big investments amount, an implementation of tar-get program is needed to resolve the large-scale issue of enhancing power quality in mains adjacent to traction substations of AC railroads.
\end{abstract}

\section{Introduction}

Russia's railroad transport is the big energy resources consumer. The railroads account for annual consumption of $5 . .6 \%$ of electrical energy (EE) generated in Russia. There is an issue of electrical energy lower quality in mains supplying traction substations (TS) of mainline railroads. A special urgency this issue acquires in east regions of Russia where the main backbone mains is immediately connected with traction substations of Trans-Siberian Railway [1-3]. Significant values of sharply alternating, non-linear and one-phase loads, and lowered levels of short circuit powers in connection points of some traction substations, result in power quality factors going beyond the permissible limits.

The results of instrumental measuring of power quality factors (PQF) indicate that on traction substations high-voltage buses of Trans-Siberian Railway there are cases of significant distortions in symmetry and voltage harmonicity [2, 3]. Average daily values of the asymmetry coefficients by the reverse sequence $k_{2 U}$ regularly reach $3 \ldots 4 \%$, while maximal ones $-6 \ldots 7 \%$; similar values for total coefficients of the harmonic components $k_{U}$ are respectively equal to: $5 \ldots 6 \%$ and $8 . .10 \%$.

Economic damage from the lower power quality comprises technological and electromagnetic components. The component is related to the fact that PQF going beyond the permissible limits can lead to disturbance of complex technological processes, deterioration in quality of products manufactured, decrease in working mechanisms productivity. The second one is determined by the following factors: increase in EE losses; decrease in machinery and equipment reliability; decrease in power accounting veracity.

The decrease in reliability is caused by accelerated thermal and electrical wear of insulation, and by failures in relay protection and automation devices at EE quality distortions $[4,5]$. The most dangerous are resonance effects on higher harmonics.

In recent years comprehensive studies have been carried out in Irkutsk State Transport University aimed at creation of methods for electrical energy systems (EES) multifunctional modeling and railroads power supply systems (RPSS) [6]. A single methodological approach was proposed to construction of EES and RPSS elements models implemented by lacelike equivalent networks. This method has been the basis for methods and computer technologies implementation, whose distinctive features are as follows [6, 7]:

- multiphasing ensuring modeling of one-phase, threephase, four-phase and six-phase systems, etc.

- multimodality which is basically a possibility of defining a wider spectrum of EES and RPSS modes: normal, emergency, unsymmetrical and unsinusoidal and limit with respect to static dead-beat stability; 
- multitasking performance which is a solution of a number of additional problems, such as determining induced voltages on adjacent power supply lines (PSL) and communication lines; calculation of electromagnetic fields strengths where the fields are created by PSL and traction networks; PSL and transformers parametric identification using the measuring data received from PMU WAMS devices; accounting of smart grid active elements when modeling EES and RPSS; taking into account superficial effect and the proximity effect when modeling electrical pathways with massive buses.

The articles provides the results of studies aimed at solution of power quality enhancement issues for mains adjacent to traction substations. To enhance power quality in mains supplying traction substations, smart grid technologies can be used together with multiagent control systems. Technical solutions, based on the results obtained, are proposed that allow to bring the power quality factors to the regulatory values.

\section{Modeling methods}

Railroads power supply systems is a unification of complex subsystems: a part of EES adjacent to TS; traction power supply system (TPSS) with $25 \mathrm{kV}$ traction network (TN) or $2 \times 25 \mathrm{kV}$ autotransformer TPSS; power supply regions (PSR) of non-traction and non-transport consumers.

Simulation methods are used for RPSS modes modeling; in this case, the time interval under study is subdivided into small spaces of time inside of which RPSS parameters are deemed unchangeable. Correlation of measurements on real objects and computer modeling results [6] indicates that the accepted assumption does not introduce noticeable errors in the calculations results. Simulation modeling algorithm includes the following stages:

- calculation of modes for schemes generated based on the set train schedule complying with discrete time moments;

- determining integral factors of modeling.

RPSS modeling algorithm is based on application of phase coordinates and lacelike equivalent networks possessing fully-meshed topology [6]. Issues of power sources, electrical loads modeling, as well as modeling of elements used to control electrical systems modes are analyzed in detail in works $[6,7]$.

To model transient processes and to form the concept of power quality smart management system, additional software was employed: Matlab and AnyLogic

\section{Methods for enhancing power quality}

The issue of power quality enhancement in mains adjacent to traction substations should be resolved by creation of RPSS modes control system. The global aim of such control is to ensure uninterrupted power efficient and quality power supply for trains traction and nontraction consumers. The implementation of this objective requires solution of the following tasks:
- ensuring voltage levels on electrically-powered rolling stock's (EPRS) load utilizing equipment that is required by regulatory documents:

- reduction of equalizing currents and power losses in traction networks and PSR to optimal values;

- compliance with GOST 32144-2013 requirements for power quality factors in points of RPSS and supplying EES common coupling.

Structural diagram of RPSS functioning is provided in fig. 1.

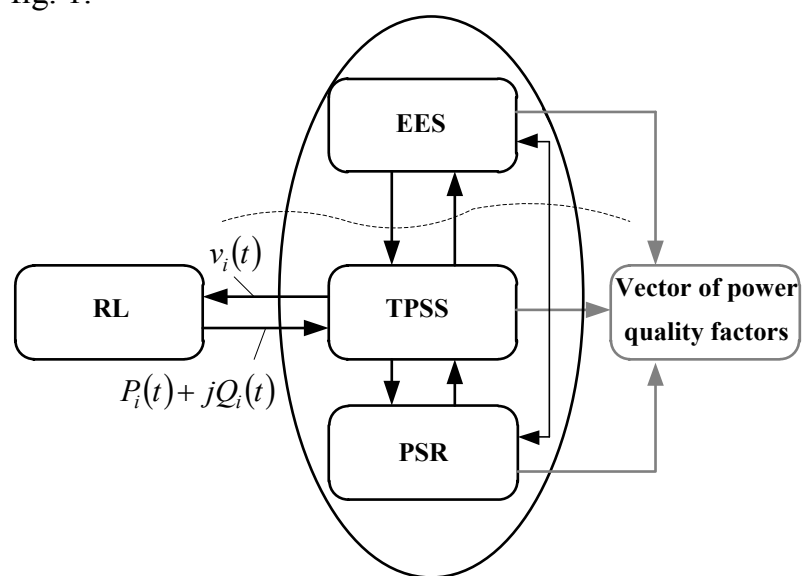

Fig. 1. Structural diagram of RPSS functioning: RL - railway line; EES - electrical energy systems; TPSS - traction power supply system; PSR - power supply regions; $\mathrm{v}(\mathrm{t})$ - trains operation speeds; $\mathrm{P}_{\mathrm{i}}(\mathrm{t})+\mathrm{jQ} \mathrm{i}(\mathrm{t})$ - traction loads

To resolve the issue of power lower quality, technical means provided in table 1 can be used. Multifunctionality of a significant part of these devices should be noted. Thus, sources of reactive power having singlephase control, can effectively be used not only for voltage levels stabilization, but for reduction in unsymmetry in supplying mains, and in mains of power supply regions of non-traction consumers. Distributed generation (DG) plants, generators of which are equipped with concordantly set excitation and frequency regulators, allow not only to stabilize voltage levels in PSR mains, but ensure the possibility of flicker removing [8]. Therefore, for a number of technical means main and additional functions can be specified, table 1 .

Controlled SRP. Due to the use of controlled SRP providing response time of $5 . .20 \mathrm{~ms}$, voltage fluctuations can significantly be reduced. Voltage deviations and fluctuations can also be reduced by energy storage devices which allow to significantly improve the indices characterizing transiency of TPSS mode [10]. 
Table 1. Main and additional functions of technical means for EE quality enhancement.

\begin{tabular}{|c|l|l|l|}
\hline No. & \multicolumn{1}{|c|}{ Solvable problem } & \multicolumn{1}{c|}{ Main technical means } & \multicolumn{1}{c|}{ Additional technical means } \\
\hline 1 & $\begin{array}{l}\text { Stabilization of traction network voltage } \\
\text { levels }\end{array}$ & $\begin{array}{l}\text { Controlled sources of reactive power } \\
\text { (SRP) of one-phase version in (TN) [1] }\end{array}$ & $\begin{array}{l}\text { Energy storage units, distributed } \\
\text { generation plants }\end{array}$ \\
\hline 2 & $\begin{array}{l}\text { Reduction in voltage deviations on buses } \\
6(10,35)-110-220 \mathrm{kV} \text { TS }\end{array}$ & $\begin{array}{l}\text { Energy storage units [9, 10], single-phase } \\
\text { controlled RPCS [1] }\end{array}$ & $\begin{array}{l}\text { DG plants, DC links, power routers [11, } \\
12]\end{array}$ \\
\hline 3 & $\begin{array}{l}\text { Reduction in voltage unsymmetry on } \\
\text { buses 6(10, 35)-110-220 kV TS }\end{array}$ & $\begin{array}{l}\text { One-phase RPCS in TN and one-phase } \\
\text { controlled RPCS on buses 6(10, 35)- } \\
110-220 \mathrm{kV} \text { TS, DC links, power routers. }\end{array}$ & $\begin{array}{l}\text { DG plants, balance-unbalance } \\
\text { transformers, balancing devices based } \\
\text { on Steinmetz scheme [13] }\end{array}$ \\
\hline 4 & $\begin{array}{l}\text { Reduction in harmonic distortions on } \\
\text { buses 6(10, 35)-110-220 kV }\end{array}$ & $\begin{array}{l}\text { Active harmonic conditioner (AHC) [1], } \\
\text { passive filters of higher harmonics }\end{array}$ & DC links, power routers \\
\hline 5 & $\begin{array}{l}\text { Flicker in networks 0.4 kV PSR when } \\
\text { DG plants available [8] }\end{array}$ & $\begin{array}{l}\text { Concordantly set excitation controllers } \\
\text { and generator rotor speed controllers [14, } \\
15]\end{array}$ & Power routers \\
\hline
\end{tabular}

A two-fold reduction in voltage unsymmetry factor can be obtained on traction substations supply voltage buses $k_{2 U}$ based on the use of one-phase controlled SRP. The extent of unsymmetry reduction depends on trains operation amounts, power of short circuit and the presence of considerable slopes in inter-substation zones.

Active harmonic conditioners. One of the most effective means to reduce harmonic distortions are active harmonics conditioners (AHC). Modeling results of railroads real power supply systems indicated that based on AHC installed on traction network branches, unsinusoidality levels on $110-120 \mathrm{kV}$ buses can be reduced to the regulatory limits [1].

Modeling of prospective modes for power supply system of one of the main railroad lines of the East Siberia indicated that without the use of power quality enhancement means, maximal values of $k_{U}$ harmonics components coefficients are found within the limits $2.3 . .23 \%$, while only for 2 of 30 TS $k_{U}$ value does not exceed the admissible limit value. For placement of 48 units of one-phase $\mathrm{AHC}$ on $27.5 \mathrm{kV}$ inputs, TS $k_{U}$ maximum on $220 \mathrm{kV}$ buses did not exceed $1.9 \%$.

Power routers. A prospective line for smart grids development is the use of power routers built with the use of high-frequency solid state transformers $[11,12]$ in power supply systems (PSS). The power router performs the following functions: power flows management; data exchange; integration of distributed generation plants in PSS [12]. In addition, power router introduction into PSS allows to enhance consumers power supply reliability and power quality. In routers connected to mid-voltage PSS, chiefly, the diagram with solid state transformer is used. Study results for power supply regions of nontraction consumers, indicated that the use of power router removes the power quality problems completely.
For the example under consideration, maximal values of $k_{U}, k_{2 U}$ coefficients reached 11 and $4 \%$ respectively on power router buses $6 \mathrm{kV}$. On $0.4 \mathrm{kV}$ power router buses these values were equal to 0.1 and $0.05 \%$.

In addition, the power router ensures a reliable integration into power supply system of distributed generation plants which includes those implemented based on renewable energy sources [12].

Flicker removal. Application of DG plants allows to achieve load shedding of networks which contributes to reduction in power losses, enhancing electrical energy reliability and quality. However, low-power generators can cause voltage fluctuations which cause flicker [16, 17]. This effect is usually manifested at an abrupt voltage drop in the DG generator connection unit [17]. The study conducted [8] indicated that the use of lookahead control algorithms in concordantly set excitation and DG frequency regulators, allows to remove flicker.

The issue of lower power quality in RPSS can effectively be resolved based on the concept of smart grids [9] and multiagent technologies [18, 19]. Structural diagram of the multiagent control system (MCS) of RPSS is provided in fig. 3 .

The multiagent system includes several interacting smart agents possessing the following characteristics:

- autonomy which means that agents, are independent at least partly;

- limitedness of representation: each one of the agents does not possess complete information about the control object in external environment, since the object is so complex that full knowledge does not have practical importance for the agent;

- decentralization: agents are absent that carry out the control of the entire object. 


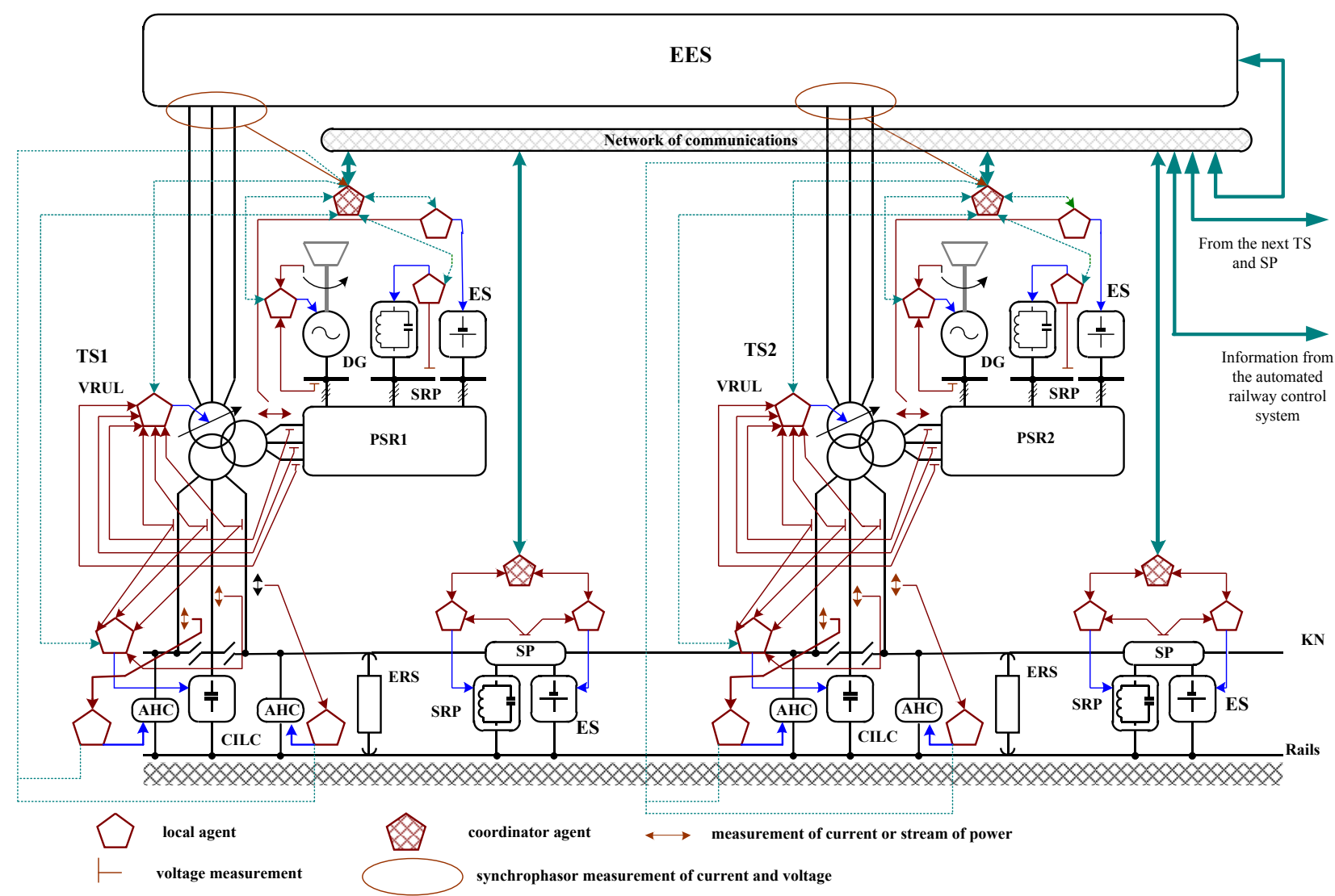

Fig. 2. MCS structural diagram: AHC - active harmonic conditioner; SRP - sources of reactive power; KN - contact network; ES energy store; SP - sectioning post; DG - distributed generation plant; VRUL - voltage regulator under load; CILC- controlled the installation of the longitudinal compensation; ERS - electro rolling stock.

Self-organization and complex behavior properties can manifest themselves in multiagent systems even under simple actions strategies of specific agents.

In the works $[18,19]$ the results of modeling a multiagent control system for distributed generation plants are presented with plants operating based on synchronous generators; the agents had the following basic set of properties in the system:

- activity - ability to organization and implementation of effects on the control object, and other agents as well;

- reactivity - perception of the object state via sensors and messages from other agents;

- autonomy - relative independence from the environment, and the presence of 'free will' possessed by some agents which determines their own behavior;

- sociability provided by advanced communication protocols and allowing an individual agent to solve its tasks jointly with others;

- purposefulness, implying the presence of their own sources of motivation.

\section{Conclusion}

The problem of lower power quality in AC railroads power supply systems can effectively be resolved based on comprehensive approach including the following segments:
- the use of technical means for PQF improvement;

- Strengthening of 110-120 kV networks supplying traction substations connected to the power centers with lower SC power level.

Due to a significant level of investments allocated for resolving the issue of lower power quality, implementation of target program is necessary which would involve the state budget funds, Russain Railways, Rosseti and private investors.

\section{References}

1. V.P. Zakaryukin, A.V. Kryukov, V.A. Ushakov, V.A. Alekseenko, Operational management in power supply systems of railways, Irkutsk: Irkutsk State Transport University, 129 p. (2012)

2. S.S. Smirnov, Higher harmonics in high voltage networks, Novosibirsk: Science, 327 p. (2010)

3. G.M. Mustafa, S.I. Gusev, A.M. Ershov et al., Calculation of the power of the active filtersymmetrizing device for the normalization of voltage on buses of the TS of $220 \mathrm{kV}$ Skovorodino, Electrical stations, No. 3, p. $46-53$ (2015)

4. I.I. Kartashev, V.N. Tulsky, R.G. Chamonov et al., Electricity Quality Management, M.: Publishing House MEI, 320 p. (2006) 
5. I.V. Zhezhelenko, A.K. Shidlovsky, G.G. Pivniak et al., Electromagnetic compatibility of consumers, M.: Mashinostroenie, 351 p. (2012)

6. V.P. Zakaryukin, A.V. Kryukov, Methods for joint modeling of traction and external power supply systems for AC railways, Irkutsk: Irkutsk State Transport University, 170 p. (2011)

7. V.P. Zakaryukin, A.V. Kryukov, Multifunctional approach to modeling of electric power systems, Modern technologies. System analysis. Modeling. No. 4 (40), p. 100-107 (2013)

8. Yu.N. Bulatov, A.V. Kryukov, K.V. Suslov, Solving the Flicker Noise Origin Problem by Optimally Controlled Units of Distributed Generation, 18th International Conference on Harmonics and Quality of Power (ICHQP). Ljubljana, Slovenia, 13-16 May (2018). DOI: 10.1109/ICHQP.2018.8378834.

9. V. Zakaryukin, A. Kryukov, A. Cherepanov, Intelligent Traction Power Supply System, International Scientific Conference Energy Management of Municipal Transportation Facilities and Transport. EMMFT 2017. Advances in Intelligent Systems and Computing, Vol. 692. Springer, Cham. pp. 91-99 (2017)

10. A.V. Kryukov, S.K. Kargapol'cev, V.P. Zakaryukin, A.V. Cherepanov, Control of traction power supply system modes, equipped with electricity storage devices, East Journal of Electronics and Communications. Vol. 17. No. 5. pp. 1185-1195 (2017)

11. Yu. Bulatov, A. Kryukov, G. Arsentyev, Application of energy routers in railway power supply systems, MATEC Web of Conferences 239, 01047 (2018), TransSiberia pp. $1-6 \quad$ (2018) DOI: 10.1051/matecconf/201823901047

12. Yu.N. Bulatov, A.V. Kryukov, G.O. Arsentiev, Use of Power Routers and Renewable Energy Resources in Smart Power Supply Systems, 2018 International Ural
Conference on Green Energy (UralCon). IEEE Conference Publications. pp. 143-148 (2018) DOI: 10.1109/URALCON.2018.8544289

13. V.P. Zakaryukin, A.V. Kryukov, I.M. Avdienko, Simulation of traction power supply systems equipped with baluns, M. Berlin: Direct Media, 168 p. (2017)

14. Yu.N. Bulatov, A.V. Kryukov, Optimization of automatic regulator settings of the distributed generation plants on the basis of genetic algorithm, 2nd International Conference on Industrial Engineering, Applications and Manufacturing (ICIEAM). IEEE Conference Publications. pp. 1-6 (2016)

15. A.V. Kryukov, S.K. Kargapol'cev, Yu.N. Bulatov, O.N. Skrypnik, B.F. Kuznetsov, Intelligent control of the regulators adjustment of the distributed generation installation, Far East Journal of Electronics and Communications, Vol. 17. No. 5. pp. 1127-1140 (2017)

16. N.I. Voropay, Distributed generation in electric power systems, [Electronic resource]: http://www.combienergy.ru/stat/983- Raspredelennayageneraciya-v-elektroenergeticheskih- sistemah.

17. Ph.P. Barker, R.W. De Mello, Determining the Impact of Distributed Generation on Power Systems: Part 1 - Radial Distribution Systems, IEEE PES Summer Meeting, Seattle, WA, USA, July 11-15, 2000, p.222$233(2000)$

18. Yu.N. Bulatov, A.V. Kryukov, A multi-agent control system of distributed generation plants, International Conference on Industrial Engineering, Applications and Manufacturing (ICIEAM), pp. 1-7 (2017).

19. Yu. N. Bulatov, A.V.Kryukov, K.V. Suslov, Multiagent technologies for control of distributed generation plants in the isolated power systems, Far East Journal of Electronics and Communications, Vol. 17. No. 5, pp. 1197-1212 (2017). 